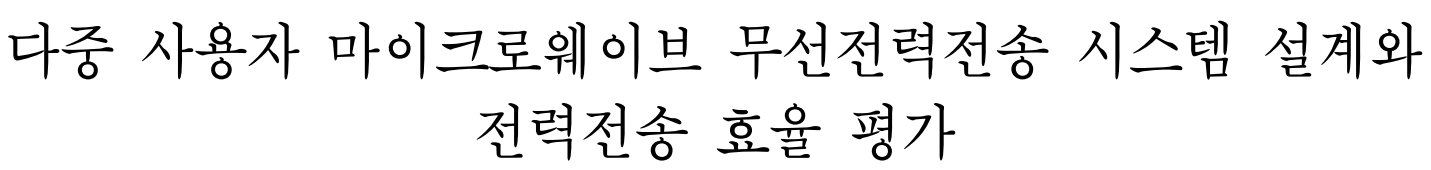

\title{
Design of Multi-User Microwave Wireless Power Transmission System and Evaluation of Its Power Transmission Efficiency
}

\author{
김 다 영 · 유 흥 균 \\ Dayoung Kim $\cdot$ Heung-Gyoon Ryu
}

요 약

본 논문에서는 Power Pilot을 기반으로 여러 사용자를 지원하는 무선 전력 전송 시스템을 구축하였다. Power Pilot은 승인된 사용자 정보 및 사용자의 전원 상태 정보를 Power Station으로 전송한다. Power Station은 가장 낮은 전원 상태의 사용자에게 먼저 가장 긴 시간 동안 전원을 전송한다. 여러 사용자를 수신하기 위한 시스템은 CDMA 시스템을 사용했으 며, 각 사용자에 전력 충전 시간을 다르게 할당하는 비균등 TDMA 시스템을 적용하였다. 이는 다수의 사용자에게 전력 우선 순위에 따라 전력 전송이 수행된다는 점에서 의미가 있다. 마지막으로, PLL 기반 RDA 시스템으로 사용자로부터 수신된 Power Pilot의 위상을 공액하여 사용자에 송신함으로써 전력 효율을 높였다. 이 세 가지 시스템을 설계하고, 시뮬 레이션을 통해 성능을 검증하여 여러 사용자를 지원하는 무선 전력 전송 시스템을 구축했다.

\section{Abstract}

In this study, a wireless power transmission system supporting multiple users was built based on a power pilot. The power pilot transmits the authorization and power status information of the user to the power station. The power station first transmits power to the user in the lowest power state for the longest time. A code-division multiple access system was used for supporting multiple receiving users and a non-uniform time-division multiple access system, which allocates power charging time differently to each user, was employed. Consequently, power was transmitted according to the power priority of multiple users. Finally, the power efficiency of the retrodirective array antenna system based on a phase-locked loop was increased by conjugating the phase of the power pilot received from the user and transmitting it to the user. We designed these three systems and verified their performance through simulations to build a wireless power transmission system that supports multiple users.

Key words: Wireless Power Transmission, Power Pilot, Multiple Access, Non-Uniform TDMA

$$
\text { I. 서 론 최근 무선통신의 발달로 시간과 공간의 제약 없이 정 }
$$

\footnotetext{
「이 논문은 2016년도 정부(교육부)의 재원으로 한국연구재단의 지원을 받아 수행된 연구이며(NRF-2016R1D1A1B01008046), 이 논문은 2019년도 한국연 구재단의 국제협력사업의 지원을 받아 연구되었음(2019K1A3A1A39102995). 또한, 이 논문은 2020년도 한국연구재단의 국제협력사업의 지원을 받아 연구되었고(2020K2A9A2A08000106), 이 논문은 충북대학교 국립대학육성사업(2019)지원을 받아 작성되었음.」 충북대학교 전자공학과(Department of Electronic Engineering, Chungbuk National University)
}

- Manuscript received June 23, 2020 ; Revised July 29, 2020 ; Accepted August 26, 2020. (ID No. 20200623-052)

· Corresponding Author: Heung-Gyoon Ryu (e-mail: ecomm@cbu.ac.kr) 
보의 접근이 가능한 시대가 열리고 있다. IoT(internet of things), 사물통신, 차량 간 통신 등 기존의 사용자 간의 서 비스뿐만 아니라, 사물간의 수많은 응용 서비스가 가능해 질 것으로 기대되고 있다. 이러한 흐름에 따라 6 세대 무 선 표준에서는 좀 더 빠르고 안정적으로 거대 연결 통신 을 구현하기 위하여 많은 연구들이 진행되고 있다 ${ }^{[1]}$. 결 과적으로 가까운 시기에 다양한 사용자, 사물, 기기들이 복잡한 선 없이도 무선으로 서로 소통하고 정보를 전달 하며 공유하게 될 것이다.

이처럼 통신 기술의 발달 및 스마트폰의 급속한 보급 으로 인하여 무선으로 영상, 음성 등의 정보를 전송함에 따라 모바일 기기의 사용량이 큰 폭으로 증가되었다. 스 마트폰의 대중화에 따라 유선충전기 없이 언제, 어디서나 자유롭게 배터리를 충전시킬 수 있는 기술이 주목받으면 서, 이제는 무선으로 에너지를 전송하는 기술인 무선전력 전송(wireless power transfer: WPT) 시대를 맞이하고 있다 [2]. 무선전력전송 기술은 라디오 주파수(radio frequency: $\mathrm{RF})$ 를 사용하는 방식이 주요 연구대상이며, 현재 다양한 기술들이 개발되고 있다. RF 신호에 담겨져 전달되는 에 너지를 이용하는 방법으로 전자파를 이용한 원거리 무선 전력 전송은 통신 기기의 이동성을 증가시킨다는 점에서

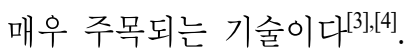

전자파를 이용한 원거리 무선 전력 전송은 이동 중에 도 언제 어디서나 충전이 가능하기 때문에 무선 통신 기 기나 $5 \mathrm{G}$ (5th generation)의 IoT 센서의 이동성을 더할 수 있는 것이 장점이다 ${ }^{[5]}$. 원거리 무선 전력 전송이 가능하 다면, 상시 충전이 가능해지기 때문에 에너지 저장장치의 용량을 줄일 수 있다.

기존의 무선전력전송 시스템은 전력전송부와 충전부 $1: 1$ 방식만 가능했다. 그러나 효율적인 RF 무선전력전송 을 위하여 1:N 충전방식 시스템 연구가 진행되어 왔다. 본 연구에서는 다수 전력 수신기에 효율적인 RF 무선전력전 송을 위한 시스템을 제시한다. Power Pilot을 기반으로 하 는 CDMA, TDMA, RDA(retrodirective array) 시스템을 설 계하였으며, 각 조건에 따라 시뮬레이션을 진행하여 시스 템 성능 분석 결과를 제시하였다. 1장 서론에 이어 2장에 서는 Power Pilot을 기반으로 하는 CDMA 시스템에 대해 설명한다. 3장에서는 Power Pilot을 기반으로 하는 TDMA
시스템을 설명하고, 4장에서는 PLL(phase locked loop) 기 반의 $\mathrm{RDA}$ 시스템의 성능을 확인하였다. 5 장에서는 비균 등 TDMA의 균등 TDMA 대비 효율을 구하여 다수 전력 수신기를 위한 무선전력전송 시스템을 구성하였다.

\section{II. 다중 사용자 무선전력전송 시스템 구성}

무선으로 에너지를 전송하는 기술인 무선전력전송은 최근 개인 휴대기기에 대한 무선 충전과 전기자동차 무 선충전을 중심으로 발전하고 있는 기술이다 ${ }^{[6]}$. 무선전력 전송 기술의 목표는 전력 전송 시에 안정성을 갖추며, 먼 전송거리와 고효율을 확보하는 것이다 ${ }^{[7][[8]}$.

그림 1 은 다중 사용자 무선전력 전송 시스템을 나타낸 다. 다중 사용자 무선전력 전송 시스템은 전력전송부와 User Device로 나뉜다. 전력전송부는 다중 사용자 수신처 리, 다중 사용자 시간 할당, 사용자의 역방향 처리 그리고 전력 저장 배터리 부분으로 나뉜다.

전력 전송부는 사용자 Device에 무선으로 전력을 전송 하는 Power Station으로, 허가된 사용자에게만 사용자의 배터리 상태에 따라 전력을 전송하는 데에 목적이 있다.

그림 2와 그림 3은 각각 다중 사용자 무선전력전송 시 스템의 파일럿 송신 및 전력 송신 방법을 나타낸다. 다중 사용자에 전력을 전송하기 위해서 전력전송부에서는 파 일럿 심볼로 수신 받은 허가된 다중 사용자를 접속하기 위한 다중 사용자 수신 처리가 필요하다. 또한, 전력 전송 부에서 사용자에 전력전송을 할 때 시간 할당 시스템을 추가적으로 구성하였다. Power pilot 심볼이란, 허가된 사 용자의 전력 상태 정보를 전력전송부에 전송하는 역할을

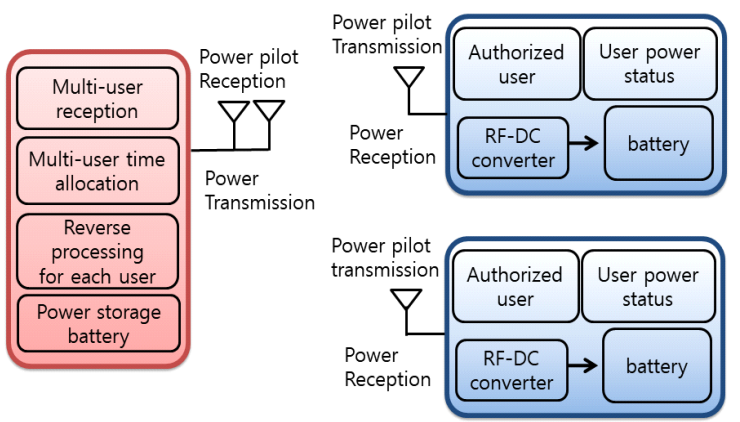

그림 1. 다중 사용자 무선전력전송 시스템

Fig. 1. Multi-user wireless power transmission system. 


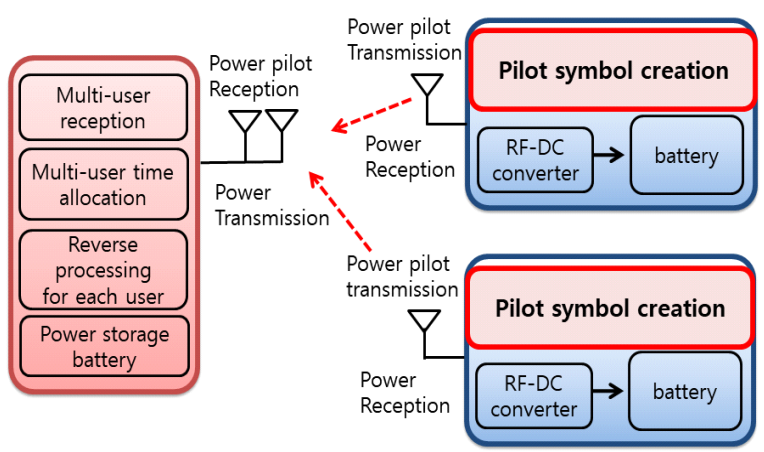

그림 2. 다중 사용자 무선전력전송 시스템의 파일럿 송신

Fig. 2. Pilot transmission of multi-user wireless power transmission system.

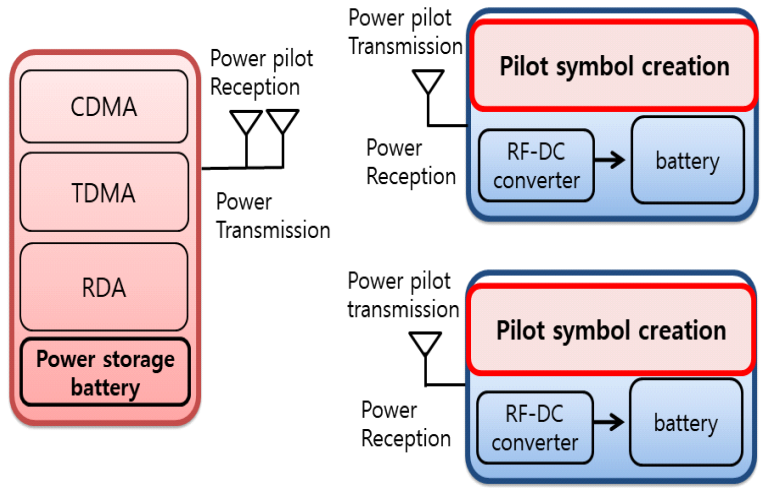

그림 3. 다중 사용자 무선전력전송 시스템의 전력송신 과정

Fig. 3. Reverse processing of each user in a multi-user wireless power transmission system.

한다. 사용자의 배터리 전력 상태에 따라 충전 우선순위 를 정하여 순위에 맞게 전력을 전송한다. 내부 시스템에 서 허가된 사용자의 전력 상태를 확인하고, $\mathrm{RDA}$ 시스템 으로 파일럿으로부터 들어온 입사각의 역방향으로 전력 을 전송한다.

표 1은 기존 시스템과 제안하는 시스템 구성의 차이를 보여준다. 제안하는 시스템은 비균등 TDMA 방법을 사용 하여 전송 효율을 개선한다. 비균등 TDMA 시스템은 사 용자로부터 받은 Power Pilot의 전력 상태에 따라 시간 할 당의 우선순위를 정한다. 동시에 4명의 다중 사용자가 Power Station으로 Power Pilot을 전송하였을 때에, 전력상
표 1. 선행연구와 비교

Table 1. Comparison with previous research.

\begin{tabular}{|c|c|}
\hline Prior research & $\begin{array}{c}\text { Proposed wireless power } \\
\text { transmission system }\end{array}$ \\
\hline CDMA system & CDMA system \\
\hline PLL based RDA system & PLL based RDA system \\
\hline Uniform TDMA system & Nonuniform TDMA system \\
\hline
\end{tabular}

태가 가장 나쁜 사용자부터 전력을 충전할 수 있도록 설 계하였다. 전력 상태가 가장 나쁜 사용자에는 가장 먼저, 가장 긴 시간으로 시간 할당을 하였으며, 전력 상태가 가 장 좋은 사용자는 마지막에 가장 짧은 시간으로 시간 할 당이 되어 전력을 충전할 수 있도록 설계하였다.

그림 4는 $\mathrm{CDMA}$ 시스템의 구성도이다. $\mathrm{CDMA}$ 시스템 의 spreading 과정을 보여준다. input symbol을 mapping하 여 spreading을 적용한다. 이는 단일 사용자일 때의 과정 이다. spreader에 사용된 코드는 각 사용자마다 다르며, 이 코드를 수신 단에서 복조하여 사용자를 구분한다.

그림 5는 PLL 구조를 이용하여 구성한 위상 공액 회로 를 보여준다. 위상 공액이란, 전파 방향을 반전시키는 것 을 뜻한다. 각 위상 공액 회로는 안테나로 들어온 신호의 위상을 반전시켜 다시 송신한다. PLL 기반의 RDA 시스 템의 회로이다. $\mathrm{Rx}$ 로 들어온 $2.45 \mathrm{GHz}$ 신호와 루프를 돌 다 Tx로 나갈 신호가 합쳐져 Band pass filter로 입력된다. 이때 Band pass filter는 필요한 신호를 필터링하기 위해 쓰였다. 필요한 부분만 필터링된 신호는 참조신호(reference signal)와 위상-주파수 검출기(phase frequency detetor)를 비교한 뒤에 루프 필터를 거쳐 $\mathrm{VCO}$ (voltage con-

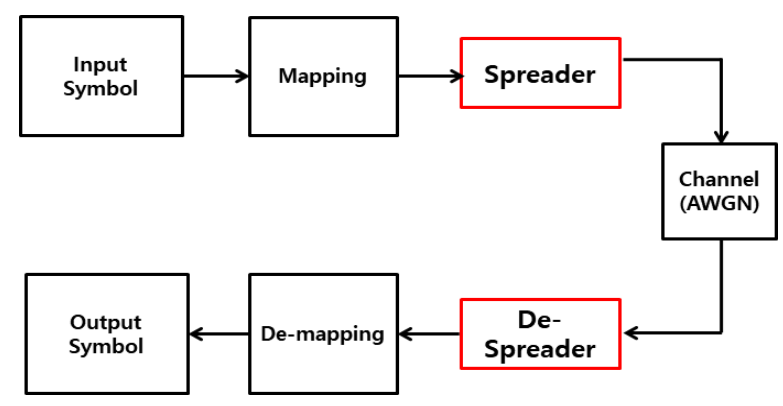

그림 4. $\mathrm{CDMA}$ 시스템의 구성도

Fig. 4. Block diagram of CDMA system. 


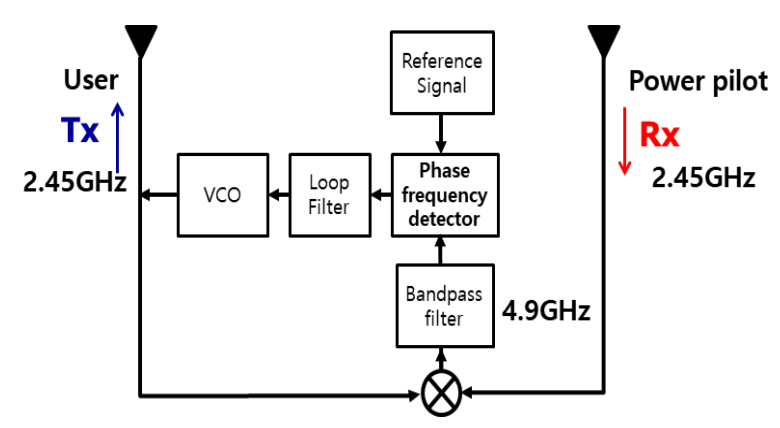

그림 5. PLL 기반의 $\mathrm{RDA}$ 시스템 구성도

Fig. 5. PLL-based RDA system configuration.

trolled oscillator)에서 신호가 생성되어 $\mathrm{Tx}$ 로 재송신한다 ${ }^{[9]}$.

\section{III. 비균등 TDMA 시스템}

무선전력전송의 경우, 안테나 이득과 같은 안테나의 특성에 따라 전력전송 효율이 영향을 받는다. 또한, 안테 나의 특성과 커플링의 영향으로 빔 생성에 문제가 발생 할 수 있다. 그러나 본 논문에서는 안테나의 특성 등 조건 이 동일하다는 가정에서 다수의 사용자에 효율적인 무선 전력전송 시스템을 위한 시간 할당 시스템을 제안하기 위하여 비균등 TDMA 시스템과 기존의 균등 TDMA 시스 템을 비교하였다.

그림 6에서 나타내듯 전력 상태는 USER1, USER2, USER3의 순서로 좋다. 이에 따라서 Time 1, Time 2, Time 3의 전력 전송 시간은 점점 짧아지며, 전력 전송 우선순 위 또한 동일하다. 전력 전송을 위한 시간 할당 시스템은 비균등 TDMA 시스템으로, 사용자의 전력 상태 우선순위 에 따라 순차적으로 전송된다.

(Time 1, Time 2, Time 3)은 충전 할당 시간을 나타낸 다. 전력 충전 시간은 Time $1>\operatorname{Time} 2>$ Time 3 의 순서로 Time 1이 가장 길다. 이 때 Power Pilot으로부터 수신된 전력량은 USER $1<\mathrm{USER} 2<\mathrm{USER} 3$ 이다. 이 경우의 수에 는 Time 1에 입력될 사용자를 A, Time 2에 입력될 사용자 를 $\mathrm{B}, \mathrm{Time} 3$ 은 $\mathrm{C}$ 로 지칭하며 $(\mathrm{A}, \mathrm{B}, \mathrm{C})$ 라고 정리하면, 그 림 7의 경우의 수가 나온다. 그림 7에서 설명하듯이, $\mathrm{A}$, $\mathrm{B}, \mathrm{C}$ 에 입력될 사용자의 전력 상태의 경우의 수는 총 여 섯 가지이다. (USER1, USER2, USER3)은 전력 상태 순서 가 USER1<USER2<USER3일 경우를 의미한다.

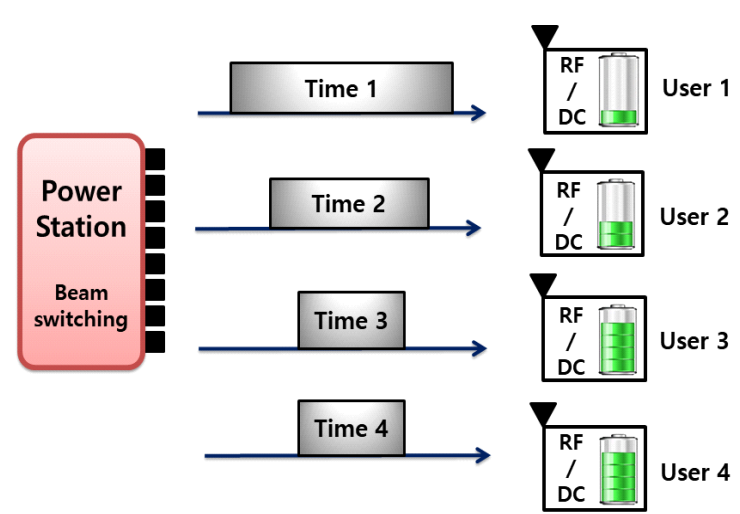

그림 6. 다중 사용자 무선전력전송 시스템의 전력 상태 에 따른 시간 할당 구성

Fig. 6. Time allocation configuration according to power status of multi-user wireless power transmission system.

$$
\begin{aligned}
P_{U S E R 1}<P_{U S E R 2}<P_{U S E R 3} \\
P_{U S E R 1}<P_{U S E R 3}<P_{U S E R 2} \\
P_{U S E R 2}<P_{U S E R 3}<P_{U S E R 1} \\
P_{U S E R 2}<P_{U S E R 1}<P_{U S E R 3} \\
P_{U S E R 3}<P_{U S E R 2}<P_{U S E R 1} \\
P_{U S E R 3}<P_{U S E R 1}<P_{U S E R 2}
\end{aligned}
$$

그림 7. 다중 사용자 무선전력전송 시스템의 전력 상태 에 따른 시간 할당 구성

Fig. 7. Power state of multi-user wireless power transmission system.

\section{$\mathrm{IV}$. 시뮬레이션 결과 및 분석}

표 2는 유저 수에 따른 $\mathrm{CDMA}$ 시뮬레이션을 위한 조 건를 나타낸다. 그림 8은 사용자가 네 명일 때에 CDMA 시스템의 BER 성능이다. 시뮬레이션 결과, 단일 사용자 일 경우와 2명 이상의 사용자인 경우, 모두 같은 BER 성 능을 가졌음을 확인하였다.

표 3은 $\mathrm{RDA}$ 시스템의 시뮬레이션 조건을 나타낸다. PLL을 기반으로 하는 역지향성 배열 안테나를 위한 PLL 기반의 위상 공액 회로를 설계하고 성능을 평가하였다. 수신 신호의 주파수는 $2.45 \mathrm{GHz}$ 이며, 재전송하는 주파수 
표 2. 유저수에 따른 $\mathrm{CDMA}$ 의 시뮬레이션 조건

Table 2. Simulation condition of CDMA according to number of users.

\begin{tabular}{|c|c|}
\hline \multicolumn{2}{|c|}{ Simulation condition } \\
\hline System & CDMA \\
\hline Symbol mapping & QPSK \\
\hline Spread length & $2,4,6,8$ bits \\
\hline Number of users & $1 \sim 4$ \\
\hline Channel & AWGN channel \\
\hline
\end{tabular}

표 3. $\mathrm{RDA}$ 시스템의 시뮬레이션 조건

Table 3. Simulation condition of RDA system.

\begin{tabular}{|c|c|}
\hline \multicolumn{2}{|c|}{ Simulation condition } \\
\hline RDA type & PLL-based RDA \\
\hline Received signal frequency & $2.45 \mathrm{GHz}$ \\
\hline Retransmitted signal frequency & $2.45 \mathrm{GHz}$ \\
\hline Filter type & Bandpass filter \\
\hline Filter center frequency & $4.9 \mathrm{GHz}$ \\
\hline Received phase & $\frac{\pi}{4}, \frac{\pi}{2}$ \\
\hline
\end{tabular}

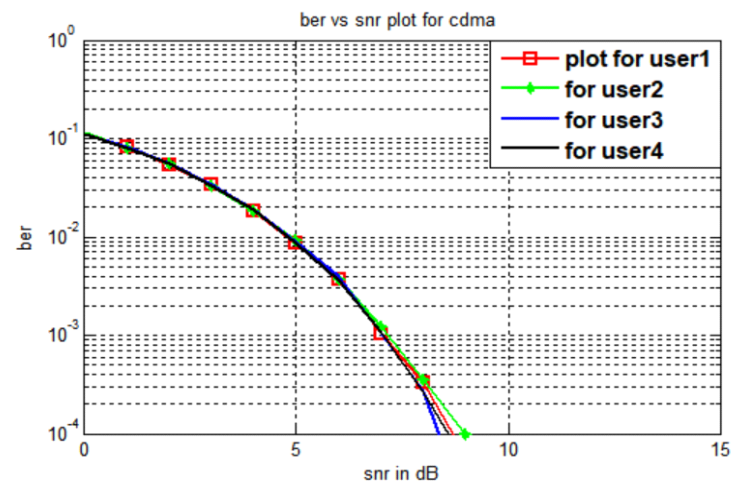

그림 8. 사용자가 네 명이고, spread length 8일 때 $\mathrm{CDMA}$ 시스템의 BER 성능

Fig. 8. BER performance of CDMA system with four users and spread length 8 .

는 $2.45 \mathrm{GHz}$ 이다.

위상 공액 회로가 정상적으로 작동할 경우, 재송신 신 호의 위상은 수신 신호가 $\pi / 4$ 일 때는 $-\pi / 4$ 가 출력된다. 그림 9 와 그림 10 은 수신 위상이 $\pi / 4$ 일 때 송신 신호의

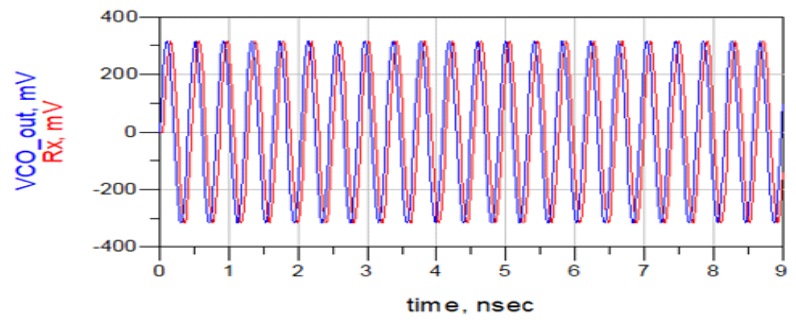

그림 9. $\pi / 4$ 일 때 본래의 신호

Fig. 9. Original signal at $\pi / 4$.

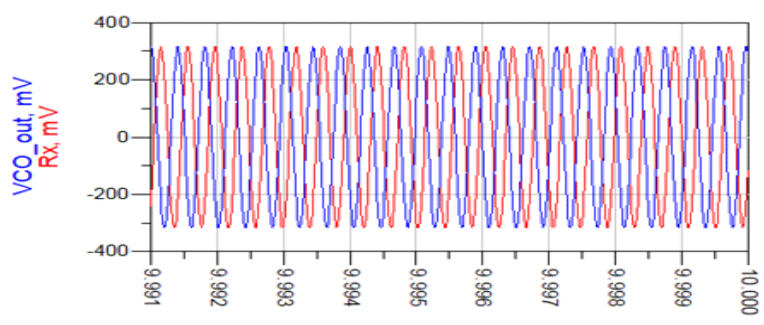

그림 10. $\pi / 4$ 일 때 위상 공액된 신호

Fig. 10. Phase-conjugated signal at $\pi / 4$.

위상 변화를 나타낸 것이다. 그림 9처럼 $\mathrm{VCO}$ 출력되는 $\mathrm{Tx}$ 지점과 초기에 Power Pilot이 입력되는 $\mathrm{Rx}$ 의 초기 위 상차는 $\pi / 4$ 이다. PLL로 위상 공액된 후에는 $\mathrm{Tx}$ 송신 신 호의 위상이 $-\pi / 4$ 가 되어 그림 10 과 같이 $\pi / 2$ 의 위상차 를 나타내게 된다.

그림 11은 1 번 사용자에 시간을 할당하는 다중 사용자 전력 전송 시뮬레이션 결과이다. Power Station에서 사용 자들의 우선순위에 따라 Beam을 Switching한다. 우선순위 는 사용자의 전력 상태에 따라 결정된다. TDMA 시스템 은 다중 사용자를 시간영역에서 사용자의 배터리 전력 상태에 따라 충전 우선순위를 정하여 순위에 맞게 전력 을 전송한다. 내부 시스템에서 허가된 사용자의 전력 상 태를 확인하고, RDA 시스템으로 파일럿으로부터 들어온 입사각의 역방향에 전력을 전송한다.

그림 12 는 사용자가 $\mathrm{N}$ 명일 때의 개선효율 공식을 나타 낸다. 각 사용자가 $100 \%$ 충전 시에 $1 \mathrm{sec}$ 가 할당된다고 하였을 때, $50 \%$ 충전 시에는 $0.5 \mathrm{sec}$ 가 할당된다. 따라서 이에 따라 개선 효율을 구할 때에 위의 공식을 대입할 수 있다. 개선 효율을 구하는 공식은 식 (1)에 나타내었다. 


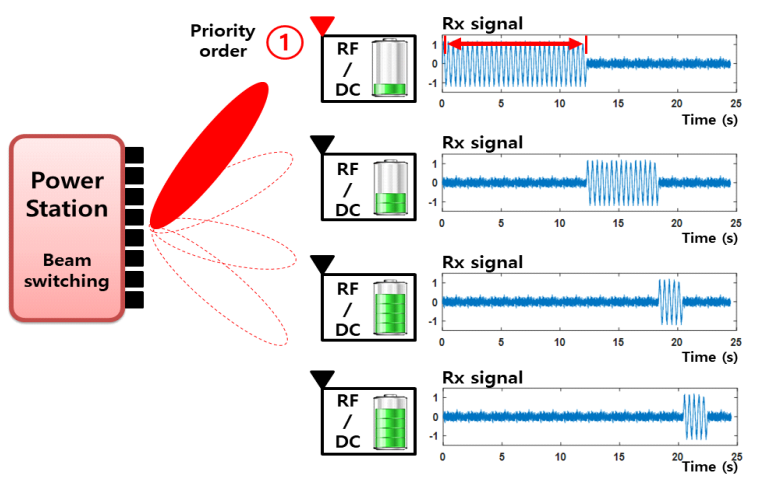

그림 11. 1번 사용자에 시간을 할당하는 다중 사용자 전 력 전송 시뮬레이션 결과

Fig. 11. Multi-user power transfer simulation results assigning time to user 1.

$$
\frac{\text { 균등 } T D M A_{n} \text { 충전시간 }}{\text { 비균등 } T D M A_{n} \text { 대충전 시간 }}=\frac{n}{n-(\mathrm{A}+\mathrm{B}+\mathrm{C})}
$$

공식에 따르면 불필요한 전력을 전송하지 않기 때문에 충전 시간이 적게 필요한 사용자를 먼저 충전할 경우의 효율도 동일한 효율이 나오게 된다.

표 4는 사용자가 3 명일 때의 효율을 정리한 표이다. 표 5 는 전력상태 $100 \%, 50 \%, 25 \%$ 인 사용자를 30명, 40명, 50 명의 경우로 나누워 개선 효율을 구하여 정리한 표이 다. 균등 TDMA 시스템은 사용자의 전력 상태를 모르기 때문에 각각의 사용자에 $100 \%$ 의 전력 충전 시간을 할당 한다.

그러나 비균등 TDMA 시스템은 Power Pilot을 통하여 사용자의 전력 상태를 미리 알고 있다. 따라서 전력 상태 에 따른 시간 할당이 가능하다. 표 4의 경우, 전력량 100 $\% 20$ 명, $50 \% 10$ 명, $25 \% 10$ 명인 경우, 개선 효율이 가장 컸음을 알 수 있다.

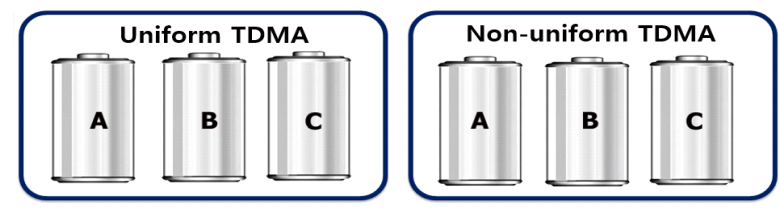

그림 12. 사용자가 $n$ 명일 때의 개선효율 예시

Fig. 12. Example of improvement efficiency when there are $n$ users.
표 4. 사용자가 3 명일 때에 개선 효율

Table 4. Improvement efficiency when there are 3 users.

\begin{tabular}{|c|c|c|c|c|c|}
\hline $\begin{array}{c}\text { User1 } \\
\text { Power } \\
\text { state }\end{array}$ & $\begin{array}{c}\text { User2 } \\
\text { Power } \\
\text { state }\end{array}$ & $\begin{array}{c}\text { User3 } \\
\text { Power } \\
\text { state }\end{array}$ & $\begin{array}{c}\text { Uniform } \\
\text { TDMA } \\
\text { charging } \\
\text { time }\end{array}$ & $\begin{array}{c}\text { Uneven } \\
\text { TDMA } \\
\text { charging } \\
\text { time }\end{array}$ & $\begin{array}{c}\text { Improve- } \\
\text { ment } \\
\text { efficiency }\end{array}$ \\
\hline 50 & 25 & 0 & 3 & 2.25 & 1.333 \\
\hline 100 & 0 & 0 & 3 & 2 & 1.5 \\
\hline 100 & 25 & 0 & 3 & 1.75 & 1.714 \\
\hline 100 & 100 & 50 & 3 & 0.5 & 6 \\
\hline
\end{tabular}

표 5. 다중 사용자의 비균등 TDMA 시스템 개선 효율 Table 5. Improved efficiency of multi-user uneven TDMA system.

\begin{tabular}{|c|c|c|c|c|c|}
\hline $\begin{array}{c}\text { Power } \\
100\end{array}$ & $\begin{array}{c}\text { Power } \\
50\end{array}$ & $\begin{array}{c}\text { Power } \\
25\end{array}$ & $\begin{array}{c}\text { Uniform } \\
\text { TDMA } \\
\text { charging } \\
\text { time }\end{array}$ & $\begin{array}{c}\text { Uneven } \\
\text { TDMA } \\
\text { charging } \\
\text { time }\end{array}$ & $\begin{array}{c}\text { Improve- } \\
\text { ment } \\
\text { efficiency }\end{array}$ \\
\hline 10 & 10 & 10 & 30 & 12.5 & 2.4 \\
\hline 10 & 10 & 20 & 40 & 20 & 2 \\
\hline 10 & 20 & 10 & 40 & 17.5 & 2.286 \\
\hline 20 & 10 & 10 & 40 & 12.5 & 3.2 \\
\hline 10 & 20 & 20 & 50 & 25 & 2 \\
\hline 20 & 10 & 20 & 50 & 20 & 2.5 \\
\hline 20 & 20 & 10 & 50 & 17.5 & 2.857 \\
\hline
\end{tabular}

\section{$\mathrm{V}$. 결 론}

본 연구에서는 다수 전력수신기에 효율적인 RF 무선 전력전송을 위한 신호설계와 시스템을 구성하였다. 기존 의 전력전송부와 충전부 $1: 1$ 방식만 가능했던 무선 전력 시스템에서, $1: \mathrm{N}$ 충전방식이 가능하게 설계된 시스템이 다. 다중 사용자를 지원하는 무선전력 전송 시스템은 Power Pilot 기반으로 설계되었다. Power Pilot은 허가된 사용자 정보와 사용자의 전력상태 정보를 Power Station 에 전송하는 역할이다. 이러한 Power Pilot으로 Power Station에서는 전력상태가 가장 낮은 사용자에 가장 먼저 가장 긴 시간으로 전력을 전송하게 된다. 비균등 TDMA 시스템은 다중 사용자를 시간영역에서 사용자의 전력 상 태에 따라 충전 우선순위를 정하여 순위에 맞게 전력을 
전송한다. 무선전력전송은 전력송신부와 수신부의 거리 가 멀수록 심해지는 감쇄로 효율이 감소된다. 따라서 사 용자의 위치에 정확하게 전력을 전송하여 효율을 높여야 한다. 그러나 본 논문에서 구성한 RDA 시스템은 단일 사 용자만을 지원하는 한계가 있다. 다수 전력 수신기에 효 율적인 시스템을 구성하기 위한 다중 사용자에 대한 $\mathrm{RDA}$ 시스템은 향후 연구되어야 할 남아있는 과제이다. 또한, 다수 전력수신기에 효율적인 RF 무선전력전송을 위 한 비균등 TDMA 시스템은 기존의 TDMA 시스템을 적용 하였을 때보다 효율이 개선되었음을 확인할 수 있었다.

\section{References}

[1] L. Dai, B. Wang, Y. Yuan, S. Han, I. Chih-lin, and Z. Wang, "Non-orthogonal multiple access for 5G: Solutions, challenges, opportunities, and future research trends, "IEEE Communications Magazine, vol. 53, no. 9, pp. 7481, Sep. 2015.

[2] X. Zhou, R. Zhang, and C. K. Ho, "Wireless information and power transfer: Architecture design and rate - energy tradeoff," IEEE Transactions on Communications, vol. 61, no. 11, pp. 4754-4767, Nov. 2013.

[3] D. W. K. Ng, E. S. Lo, and R. Schober, "Wireless information and power transfer: Energy efficiency optimization in OFDMA systems," IEEE Transactions on Wireless Communications, vol. 12, no. 12, pp. 6352-6370,

김 다 영 [충북대학교 전자공학부/석사]

https://orcid.org/0000-0001-5339-4347

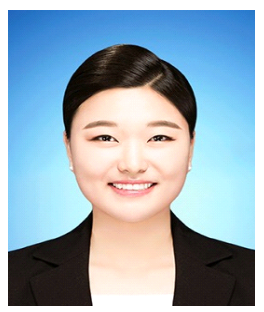

2018년 2월: 충북대학교 전자공학과(공학 사)

2018년 8월: 충북대학교 전자공학과 (공학 석사)

[주 관심분야] 무선통신 시스템, 신호처 리, $\mathrm{B} 5 \mathrm{G}$ 이동통신 시스템
Dec. 2013.

[4] Y. Zeng, B. Clerckx, and R. Zhang, "Communications and signal design for wireless power transmission," IEEE Transactions on Communications, vol. 65, no. 5, pp. 2264-2290, May 2017.

[5] S. Kim, J. Kim, J. Kim, G. Kim, and J. Yu, "Retrodirective array antenna with parabolic shape structure for short-range microwave power transfer," in 2019 IEEE International Symposium on Antennas and Propagation and USNC-URSI Radio Science Meeting, Atlanta, GA, 2019, pp. 1799-1800.

[6] R. Y. Miyamoto, T. Itoh, "Retrodirctive arrays for wireless communications," IEEE Microwave Magazine, vol. 3, no. 1, pp. 71-79, Mar. 2002.

[7] Study on New Radio(NR) Access Technology Physical Layer Aspects, 3GPP TR 38.802, v. 14.2.0, Sep. 2017.

[8] K. W. Choi, D. I. Kim, and M. Y. Chung, "Received power-based channel estimation for energy beamforming in multiple-antenna RF energy transfer system," IEEE Transactions on Signal Processing, vol. 65, no. 6, pp. 1461-1476, Mar. 2017.

[9] V. Fusco, C. B. Soo, and N. Buchanan, "Analysis and characterization of PLL-based retrodirective array," in IEEE Transactions on Microwave Theory and Techniques, vol. 53, no. 2, pp. 730-738, Feb. 2005.

유 흥 균 [충북대학교 전자공학부/교수]

https://orcid.org/0000-0002-7368-9860

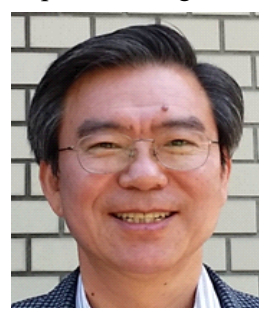

1988년 현재: 충북대학교 전자공학부 교 수

2002년 3월 2004년 2월: 충북대학교 컴 퓨터정보통신연구소 소장

[주 관심분야] 무선통신시스템, 위성통신, $\mathrm{B} 5 \mathrm{G} / 6 \mathrm{G}$ 이동통신 시스템, 통신회로 설 계 및 통신 신호처리 